\title{
EDITORIAL
}

\section{Introduction to Spreading Depolarizations: Special Edition of Neurocritical Care}

\author{
Ramani Balu ${ }^{\top}$ and Brandon Foreman ${ }^{2 *}$
}

๑ 2021 Springer Science+Business Media, LLC, part of Springer Nature and Neurocritical Care Society

Spreading depolarization (SD) of brain tissue is one of the most common, dramatic, and mysterious physiologic events in the central nervous system [1, 2]. Seemingly all at once, the charge polarization of neuronal and glial cell membranes completely dissipates, silencing normal brain electrical activity and creating widespread changes in volume, flow, and metabolism. These massive depolarizations are akin to a dam bursting open, and they propagate across the cerebral cortex like tsunamis at speeds of approximately $3 \mathrm{~mm} / \mathrm{min}$. The dissipation of charge within neural tissues during SDs flattens electroencephalographic signals and sparks a scramble of adenosine-triphosphate (ATP)-dependent activity aimed at restoring normal membrane gradients in their wake. First described in the 1940s, SDs were viewed for decades as a physiological curiosity. However, a multitude of studies since Leao's initial description [3] have linked SDs to the pathophysiology of some of the most prevalent neurological diseases, including migraine, stroke, anoxic brain injury, and traumatic brain injury. Nearly 60 years after their initial description in the laboratory, the first confirmation of the occurrence of SDs in the injured human neocortex was reported in patients undergoing subdural electrocorticography [4], cementing their clinical relevance and ushering a new era of translational SD research.

Much foundational translational work has been done under the leadership and inspiration of the Co-Operative Studies on Brain Injury Depolarizations (http://www. cosbid.org/) consortium. Co-Operative Studies on Brain Injury Depolarizations studies have convincingly demonstrated that SDs occur with high frequency in nearly all

\footnotetext{
*Correspondence: foremabo@ucmail.uc.edu

${ }^{2}$ Department of Neurology, University of Pennsylvania, Philadelphia, PA, USA

Full list of author information is available at the end of the article
}

types of acute brain injuries [5]. The energetic demands of reestablishing membrane potential gradients after SDs creates a mismatch between metabolic supply and demand [6], leading to significant physiologic distress [7] and the potentiation of secondary brain injuries. Further, SDs have been linked directly with cytotoxic edema formation and lesion expansion after acute brain injuries [8, 9], and increasingly, data suggest that SDs may impact clinical outcome [10].

Particularly in clinical practice, SDs represent a profoundly underrecognized marker as well as mediator of secondary brain injury. Therapies that target SDs have immense potential to limit brain damage and improve outcomes [11, 12]. In addition, care guided by SD monitoring may enable a "physiological precision medicine" approach to intensive care unit management, in which specific SD-modulating therapies that may have limited or no efficacy across an entire undifferentiated cohort can be successfully deployed in the right subsets of patients $[5,13]$.

In this special edition of Neurocritical Care, we are excited to present two volumes of work spanning the current state of the science of SD research. Articles demonstrating an increasingly firm link with delayed cerebral ischemia [14] and putative associations with subdural hematomas expand the clinical relevance of SDs [15, 16]. Translational efforts provide new data on the development of cytotoxic edema that results from SD [17], Hartings et al. [unpublished]), and a review of historical literature calls into question our assumptions about secondary brain injury development through glutamate excitotoxicity (Andrew et al. [unpublished]). Depolarization of neural tissue is an inciting event that starts the clock on cell death machinery, and work in anoxic brain injury highlights the importance of SD and their potential as a diagnostic or therapeutic target in patients suffering cardiac arrest (Han et al. [unpublished]). Finally,

\section{Springer}


practical efforts to reliably detect SD in the intensive care unit setting are represented through exciting new tools that can be used at the bedside [18].

Detecting events that impact brain injury recovery, such as elevations in intracranial pressure and nonconvulsive seizures, is the cornerstone of modern neurocritical care. In this edition, we find evidence that SDs are twice as common as seizures in our patients (Foreman et al. [unpublished]), yet their impact is just being elucidated [10]. In the not-too-distant future, we envision noninvasive automated SD detection methods that will alert teams in real time, and the development of novel treatment strategies that will lead to a reduction in secondary brain injuries and improvement in outcomes. For those familiar with the science of SDs, this edition offers new perspectives and novel research that furthers the field. For those just beginning to acclimate to the scope and relevance of this phenomenon, we hope this edition provides a point of reference to dive into the rich literature supporting the physiologic and clinical importance of SDs in neurocritical care.

\section{Author details \\ Conflict of interest \\ None. \\ Source of support \\ None.}

${ }^{1}$ University of Cincinnati Gardner Neuroscience Institute, Cincinnati, OH, USA.

2 Department of Neurology, University of Pennsylvania, Philadelphia, PA, USA.

\section{Publisher's Note}

Springer Nature remains neutral with regard to jurisdictional claims in published maps and institutional affiliations.

Published online: 17 October 2021

\section{References}

1. Dreier JP. The role of spreading depression, spreading depolarization and spreading ischemia in neurological disease. Nat Med. 2011;17(4):439-47.

2. Lauritzen M, Dreier JP, Fabricius M, Hartings JA, Graf R, Strong AJ. Clinical relevance of cortical spreading depression in neurological disorders: migraine, malignant stroke, subarachnoid and intracranial hemorrhage, and traumatic brain injury. J Cereb Blood Flow Metab. 2011;31(1):17-35

3. Leao AAP. Spreading depression of activity in the cerebral cortex. J Neurophysiol. 1944;7(6):359-90.

4. Strong AJ, Fabricius M, Boutelle MG, Hibbins SJ, Hopwood SE, Jones $\mathrm{R}$, et al. Spreading and synchronous depressions of cortical activity in acutely injured human brain. Stroke. 2002;33(12):2738-43.

5. Hartings JA. Spreading depolarization monitoring in neurocritical care of acute brain injury. Curr Opin Crit Care. 2017;23(2):94-102.

6. Ayata C, Lauritzen M. Spreading depression, spreading depolarizations, and the cerebral vasculature. Physiol Rev. 2015;95(3):953-93.

7. Hinzman JM, Wilson JA, Mazzeo AT, Bullock MR, Hartings JA. Excitotoxicity and metabolic crisis are associated with spreading depolarizations in severe traumatic brain injury patients. J Neurotrauma. 2016;33(19):1775-83.

8. Hartings JA, Shuttleworth CW, Kirov SA, Ayata C, Hinzman JM, Foreman $B$, et al. The continuum of spreading depolarizations in acute cortical lesion development: examining Leão's legacy. J Cereb Blood Flow Metab. 2017;37(5):1571-94.

9. Dreier JP, Lemale CL, Kola V, Friedman A, Schoknecht K. Spreading depolarization is not an epiphenomenon but the principal mechanism of the cytotoxic edema in various gray matter structures of the brain during stroke. Neuropharmacology. 2018;134:189-207.

10. Hartings JA, Andaluz N, Bullock MR, Hinzman JM, Mathern B, Pahl C, et al. Prognostic value of spreading depolarizations in patients with severe traumatic brain injury. JAMA Neurol. 2020;77(4):489-99.

11. Hertle DN, Dreier JP, Woitzik J, Hartings JA, Bullock R, Okonkwo DO, et al. Effect of analgesics and sedatives on the occurrence of spreading depolarizations accompanying acute brain injury. Brain. 2012;135(Pt 8):2390-8.

12. Carlson AP, Abbas M, Alunday RL, Qeadan F, Shuttleworth CW. Spreading depolarization in acute brain injury inhibited by ketamine: a prospective, randomized, multiple crossover trial. J Neurosurg. 2019;130(5):1513-9.

13. Helbok R, Hartings JA, Schiefecker A, Balanca B, Jewel S, Foreman B, et al. What should a clinician do when spreading depolarizations are observed in a patient? Neurocrit Care. 2020;32(1):306-10.

14. Kawano A, Sugimoto K, Nomura S, Inoue T, Kawano R, Oka F, et al. Association between spreading depolarization and delayed cerebral ischemia after subarachnoid hemorrhage: post hoc analysis of a randomized trial of the effect of cilostazol on delayed cerebral ischemia. Neurocrit Care. 2021. https://doi.org/10.1007/s12028-021-01330-0.

15. Meadows C, Davis H, Mohammad L, Shuttleworth CW, Torbey M, Zhu Y, et al. Spreading depolarization after chronic subdural hematoma evacuation: associated clinical risk factors and influence on clinical outcome. Neurocrit Care. 2021. https://doi.org/10.1007/s12028-021-01339-5.

16. Robinson D, Hartings J, Foreman B. First report of spreading depolarization correlates on scalp eeg confirmed with a depth electrode. Neurocrit Care. 2021. https://doi.org/10.1007/s12028-021-01360-8.

17. Hellas JA, Andrew RD. Neuronal swelling: a non-osmotic consequence of spreading depolarization. Neurocrit Care. 2021. https://doi.org/10.1007/ s12028-021-01326-w.

18. Jewell S, Hobson S, Brewer G, Rogers M, Hartings JA, Foreman B, et al. Development and evaluation of a method for automated detection of spreading depolarizations in the injured human brain. Neurocrit Care. 2021. https://doi.org/10.1007/s12028-021-01228-x. 